\title{
LOEFFLER'S ENDOCARDITIS DUE TO IDIOPATHIC HYPEREOSINOPHILIC SYNDROME
}

\author{
HYUCK-JUN YOON, MD, HYUNGSEOP KIM, MD, HYOUNG-SEOB PARK, MD, YUN-KYEONG CHO, MD, \\ CHANG-WOOK NAM, MD, SEONG-WOOK HAN, MD, SEUNG-HO HUR, MD, YOON-NYUN KIM, MD \\ AND KWON-BAE KIM, MD
}

DIVISION OF CARDIOLOGY, DEPARTMENT OF INTERNAL MEDICINE, DONGSAN MEDICAL CENTER, KEIMYUNG UNIVERSITY, DAEGU, KOREA

Loeffler's endocarditis, a rare cardiac manifestation of hypereosinophilic syndrome (HES), is characterized by fibrous thickening of the endocardium of both ventricles, leading to apical obliteration and heart failure. We report a case of a 41year-old male with slowly progressive right-sided heart failure symptoms. The complete blood count showed hypereosinophilia and the echocardiogram revealed that the both ventricles were filled with large amount of thrombus. His symptoms and typical echocardiographic findings markedly improved within several weeks after steroid and anticoagulation therapy.

KEY WORDS: Loeffler's endocarditis · Hypereosinophilic syndrome.

\section{INTRODUCTION}

Hypereosinophilic syndrome (HES) is a rare disease characterized by persistent eosinophilia (>1,500 eosinophils $\times$ $10^{6} / \mathrm{L}$ ) for at least 6 months that remains unexplained in spite of a comprehensive evaluations and evidence of organ dysfunction primarily attributed to the eosinophilia. ${ }^{1)}$ Loeffler's endocarditis is a myocardial disease, thought to be secondary to idiopathic hypereosinophilia and often secondary to infection, medication or clonal disorders such as acute leukemia. ${ }^{2 / 3)}$ It is characterized by fibrous thickening of the endocardium of one or both ventricles, leading to apical obliteration and restrictive cardiomyopathy, resulting in heart failure, thromboembolic event and/or atrial fibrillation. ${ }^{3)}$ Prognosis is believed to be poor due to high mortality from heart failure, sudden death or thromboembolism. The reported 10 -year survival rate is less than $50 \%$, which is especially lower in corticosteroid resistant cases with cardiac involvement. ${ }^{4) 5}$

Here, we present a patient who presented with anasarca, peripheral hypereosinophilia, and typical echocardiographic findings consistent with Loeffler's endocarditis, which disappeared with corticosteroid and anticoagulation therapy.

\section{CASE}

A 41-year-old male visited our hospital for recently progressed generalized edema and abdominal distension. He had a history of persistent malaise and fatigue for 3 months. Prior to the this first visit, he had been admitted for ascites control at the other hospital for several days, but he did not have a favorable response to conventional diuretic therapy. On his visit, vital signs were stable; blood pressure, 120/80 $\mathrm{mmHg}$; pulse rate, $78 \mathrm{bpm}$; respiratory rate, $18 / \mathrm{min}$ and body temperature, $36.5^{\circ} \mathrm{C}$. Physical examination revealed jugular venous distension in the sitting position, decreased breaths sound in the bilateral lower lung fields, severely distended abdomen with shifting dullness on percussion and pretibial pitting edema. Chest X-ray revealed cardiomegaly and blunting of bilateral costophrenic angles. Electrocardiography demonstrated normal sinus rhythm with low voltage in the limb leads. Laboratory studies showed marked eosinophilia $\left(5,060 \times 10^{6} / \mathrm{L}\right)$, mild elevated cardiac enzyme (troponin-I $0.57 \mathrm{mg} / \mathrm{mL}$ ), mild elevated liver enzyme (total bilirubin $2.5 \mathrm{mg} / \mathrm{dL}$, alkaline phosphatase $144 \mathrm{U} / \mathrm{L})$ and elevated C-reactive protein $(2.43 \mathrm{mg} / \mathrm{dL})$. But serum electrolyte level and thyroid functions were 
within normal limits. No parasite or ova were seen on stool examination. A bone marrow biopsy showed normocellularity with eosinophilic hyperproliferation, and a fluorescence in situ hybridization test for FIP1L1-PDGFRA tyrosine kinase also demonstrated no evidence of abnormal myeloid maturation or lymphoproductive disorder.
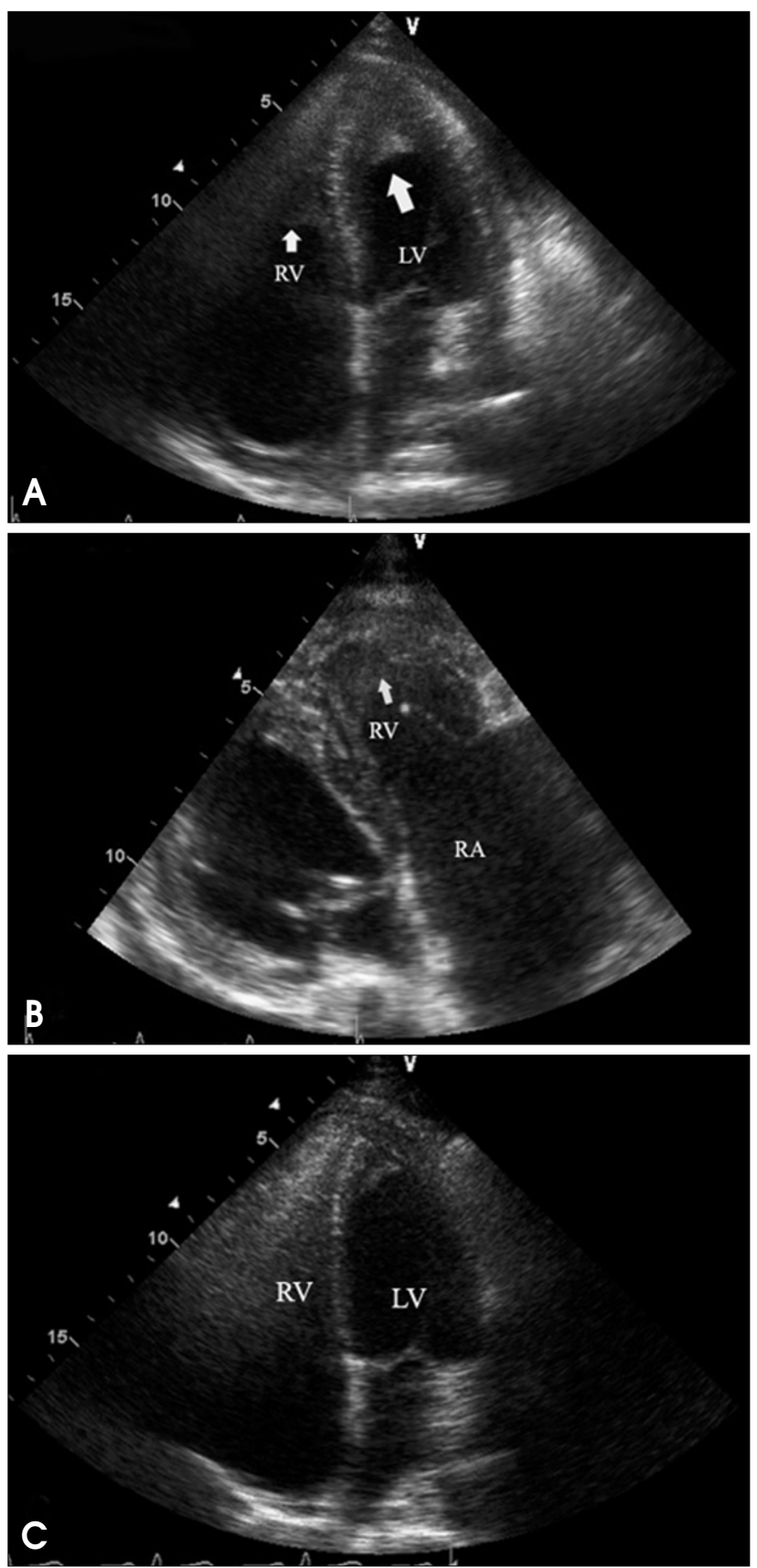

Fig. 1. Apical 4 chamber view of initial echocardiography showed apical homogeneous materials (arrows) suggestive of thrombi in the both ventricles (A). Right ventricular inflow view of initial echocardiography showed severe right atrial enlargement and large amount of thrombus filling in right ventricle (B). Apical 4 chamber view of follow up on the $15^{\text {th }}$ hospital day showed marked resolution of thrombus at both ventricular apices (C).
Two-dimensional (2D) echocardiography revealed preserved left ventricular ejection fraction $(>55 \%)$ with reduced systolic tissue Doppler velocity (TDV) of septal mitral annulus; $\mathrm{Sm}, 4 \mathrm{~cm} / \mathrm{sec}$ and diastolic TDV of septal mitral annulus; Em, $4 \mathrm{~cm} / \mathrm{sec}$, and also showed finding of diastolic dysfunction; E/E', 15.4, E/A, 0.8. In color Doppler imaging, there was no significant tricuspid regurgitation, but the inferior vena cava was distended independent of respiration. However, a small amount of pericardial effusion and both ventricular apical obliteration by homogeneous echogenic materials suggestive of thrombus extending mid lateral and into the septal area were noted; both atria, particularly the right atrium, were markedly distended in contrast to the normal to small sized ventricles (Fig. 1A and B). Chest computerized tomography was performed to rule out pulmonary thromboembolism and lymphoma, and it revealed no specific mass or lymph node enlargement without an evidence of thromboembolism. However apical obliteration of both ventricles by non-enhanced homogenous materials and presence of same material in right atrium were noted (Fig. 2).

The patient was treated with oral corticosteroid (prednisolone $30 \mathrm{mg}$ ) and anticoagulation by intravenous infusion of unfractionated heparin, which was switched to warfarin on the $3^{\text {rd }}$ hospital day. Also intravenous furosemide (20-40 $\mathrm{mg} /$ day) was administered to control ascites and edema. On the $2^{\text {nd }}$ day of treatment with corticosteroid, peripheral eosinophilic counts decreased to a normal range $(186 \times$ $10^{6} / \mathrm{L}$ ) and peripheral edema was markedly improved. After a week of corticosteroid treatment, we attempted steroid tapering to $10 \mathrm{mg}$ of prednisolone but because of fluctuations in eosinophilic counts, the initial dose was restarted and maintained.

Follow up 2D echocardiography on the $15^{\text {th }}$ hospital day showed marked resolution of thrombus at both ventricular apices (Fig. 1C).

However, tissue Doppler velocity (TDV) of septal mitral annulus had no interval change compared to the initial tissue Doppler study. Additional follow up echocardiography at 2 months later did not show further resolution of the diastolic dysfunction. The patient was continued on corticosteroid and oral anticoagulation therapy.

\section{DISCUSSION}

In this report, we present a case consistent with Loeffler's endocarditis secondary to idiopathic HES. In these patient group, heart is the most frequently involved organ (50$60 \%$ in cases). ${ }^{6}$ Loeffler's endocarditis is thought to be a late cardiac manifestation that is characterized by fibrous thickening of the endocardium and extensive eosinophilic 


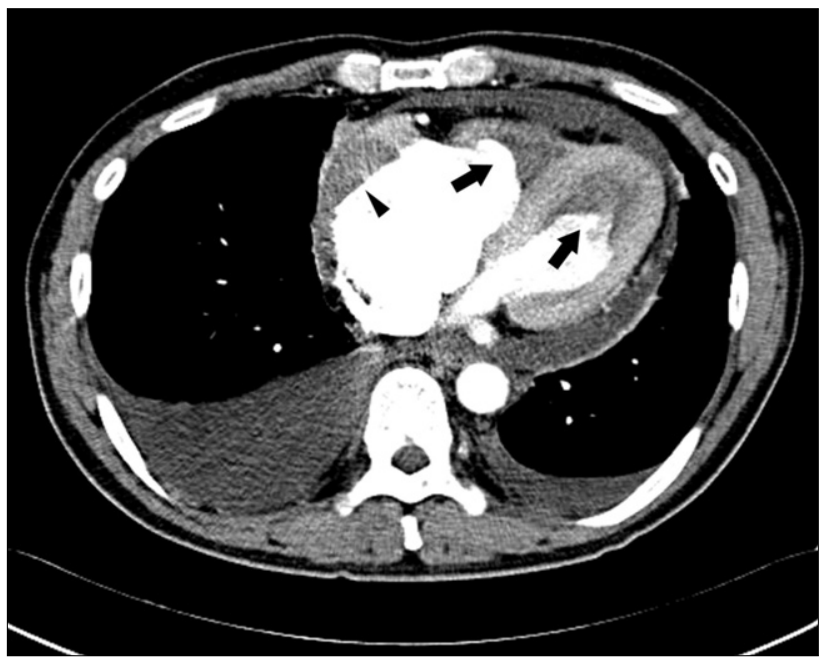

Fig. 2. Computerized tomography of the chest showed apical obliterations of both ventricles by non-enhanced homogenous materials (arrow) consistent with the echocardiographic findings. The nonenhanced density material (arrowhead) was also noted in the enlarged right atrium.

infiltration of the ventricular endocardium, with subsequent degranulation and necrosis with resultant endomyocardial fibrosis, leading to apical thrombotic obliteration. In addition, the intensive inflammatory changes result in superimposed thrombus formation, which subsequently occupies much of the ventricular cavity. ${ }^{7-9)}$ The presence of asymptomatic endomyocardial lesions may precede overt cardiac disease by a substantial period of time. ${ }^{10)}$ Valvular involvement, as well as endocardial involvement, includes tricuspid, mitral, and aortic valve regurgitation caused by endocardial inflammation, and fibrosis affecting papillary muscles and chordae tendineae producing papillary muscle dysfunction. ${ }^{11)}$

For the treatment of symptomatic patients with HES, such as in the case of Loeffler's endocarditis, the first line drug of choice is corticosteroid, followed by cytotoxic agents such as hydroxyurea or immunomodulatory agents such as interferon-alpha. ${ }^{212) 13)}$ Gene rearrangements that activate tyrosine kinase may cause a myeloid disorder, which can be treated with imatinib mesylate. ${ }^{14)}$ Glucocorticoid treatment has resulted in clinical and biopsy-proven improvement of eosinophilic infiltration and myocardial damage as well as normalization of peripheral hypereosinophilia. Thus, normalizing the peripheral eosinophilic count has been accepted as one of the initial therapeutic targets. Treatment with glucocorticoid (prednisolone 40-60 mg/day) has been used, and along with conventional treatment of heart failure and maintenance therapy with a lower dose of $10 \mathrm{mg} /$ day, appears to prevent progression of cardiac disease. ${ }^{1115)}$

The vast majorities of the literature emphasize the importance of oral anticoagulation because infiltration and degranulation of eosinophils in the endocardium induce an inflammatory and prothrombotic state that frequently results in the development of a ventricular mural thrombus. Consequently, anticoagulation therapy should be also considered before the ventricular obliteration develops. These findings were supported by those of Lofiego et al. who reported five patients with Loeffler's endocarditis, including three patients with long-term echocardiographic follow-up. ${ }^{7)}$ This report showed that appropriate anticoagulation therapy with a corticosteroid or a cytotoxic agent (in the case of eosinophilic leukemia) not only prevented pulmonary or systemic embolic events and thrombus growth but also limited the obliteration of the ventricular cavity, thereby inducing a favorable long-term left

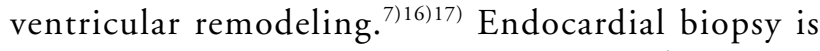
recommended as an invasive diagnostic tool. ${ }^{18)}$ However, this case showed definite peripheral hypereosinophilia and typical echocardiographic findings, therefore another invasive diagnostic tool would not be needed to make a diagnosis. To facilitate the choice of appropriate treatment regimens, studies to determine possible secondary causes of hypereosinophilia are also important. For instance, parasitic or other infections, and clonal disorders such as acute leukemia and lymphoma are one of the causes of secondary hypereosinophilia. ${ }^{2)}$ In this case, possible causes of secondary HES were ruled out, and then we finally could confirm Loeffler's endocarditis due to idiopathic HES. Remnant thrombus in both apices, rigidity of mitral and tricuspid valve and diastolic dysfunction persisted despite the initial favorable response to medical therapy. The patient remains on drug therapy and serial follow up echocardiography is also planned. In the future, more studies will be needed to evaluate the efficacy of medical therapies that would not only result in hematologic remission of HES but also to bring out full recovery of end organ damage without remnant sequelae.

\section{REFERENCES}

1. Chusid MJ, Dale DC, West BC, Wolff SM. The hypereosinophilic syndrome; Analysis of fourteen cases with review of the literature. Medicine 1975;54:1-27.

2. Tefferi A, Patnaik MM, Pardanani A. Eosinophilia: secondary, clonal and idiopathic. Br J Haematol 2006;133:468-92.

3. Corssmit EP, Trip MD, Durrer JD. Loeffler's endomyocarditis in the idiopathic hypereosinophilic syndrome. Cardiology 1999;91:272-6.

4. Gupta PN, Valiathan MS, Balakrishnan KG, kartha CC, Ghosh MK. Clinical course of endomyocardial fibrosis. Br Heart J 1989;62:450-4.

5. Chao BH, Cline-Parhamovich K, Grizzard JD, Smith TJ. Fatal Loeffler's endocarditis due to hypereosinophilic syndrome. Am J Hematol 2007;82: 920-3.

6. Weller PF, Bubley GJ. The idiopathic hypereosinophilic syndrome. Blood 1994;83:2759-79.

7. Lofiego C, Ferlito M, Rocchi G, Biagini E, Perugini E, Branzi A, 
Rapezzi C. Ventricular remodeling in Loeffler endocarditis: implications for therapeutic decision making. Eur J Heart Fail 2005;7:1023-6.

8. Salanitri GC. Endomyocardial fibrosis and intracardiac thrombus occurring in idiopathic hypereosinophilic syndrome. Am J Roentgenol 2005; 184: 1432-3.

9. Alter P, Maisch B. Endomyocardial fibrosis in Churg-Strauss syndrome assessed by cardiac magnetic resonance imaging. Int J Cardiol 2006;108: $112-3$.

10. Borer JS, Henry WL, Epstein SE. Echocardiographic observations in patients with systemic infiltrative disease involving the heart. Am J Cardiol 1977;39:184-8.

11. Parrillo JE, Borer JS, Henry WL, Wolff SM, Fauci AS. The cardiovascular manifestations of the hypereosinophilic syndrome. Prospective study of 26 patients, with review of the literature. Am J Med 1979;67:572-82.

12. Klion AD. Approach to the treatment of hypereosinophilic syndrome. Immunol Allergy Clin North Am 2007;27:551-60.

13. Lombardi C, Rusconi C, Faggiano P, Lanzani G, Campana C, Arbustini E. Successful reduction of endomyocardial fibrosis in a patient with idiopathic hypereosinophilic syndrome: A case report. Angiology 1995; 46:345-51.
14. Cools J, DeAngelo DJ, Gotlib J, Stover EH, Legare RD, Cortes J, Kutok J, Clark J, Galinsky I, Griffin JD, Cross NC, Tefferi A, Malone J, Alam R, Schrier SL, Schmid J, Rose M, Vandenberghe P, Verhoef G, Boogaerts M, Wlodarska I, Kantarjian H, Marynen P, Coutre SE, Stone R, Gilliland DG. A tyrosine kinase created by fusion of the PDGFRA and FIP1L1 genes as a therapeutic target of imatinib in idiopathic hypereosinophilic syndrome. N Engl J Med 2003;348:1201-14.

15. Butterfield JH. Treatment of hypereosinophilic syndromes with prednisone, hydroxyurea, and interferon. Immunol Allergy Clin North Am 2007;27: 493-518.

16. Benezet-Mazuecos J, Marcos-Alberca P, Farré J, Orejas M, de la Fuente A, Prieto E. Images in cardiovascular medicine. Early differential resolution of right and left ventricular obliteration in Loeffler endocarditis after chemotherapy and anticoagulation. Circulation 2006;114:e635-7.

17. Benezet-Mazuecos J, de la Fuente A, Marcos-Alberca P, Farre J. Loeffler endocarditis: what have we learned? Am J Hematol 2007;82:861-2.

18. Morimoto S, Kubo N, Hiramitsu S, Uemura A, Ohtsuki M, Kato Y, Sugiura A, Miyagishima K, Mori N, Yoshida Y, Hishida H. Changes in the peripheral eosinophil count in patients with acute eosinophilic myocarditis. Heart Vessels 2003;18:193-6. 